\title{
Assessing the Clinical Utility of Haptoglobin to Creatinine Ratio as a Test for Detecting Nephropathy among Type 2 Diabetic Patients
}

\author{
Mohammed $\mathrm{IY}^{1 *}$, Busari $\mathrm{AO}^{2}, \mathrm{Ahmad} \mathrm{MB.}^{2}$ \\ ${ }^{\prime}$ Department Chemical pathology and Department of Medical Laboratory Science, Bayero University Kano, Kano \\ *Corresponding Author: Mohammed Idris Yahaya. Department Chemical pathology, Bayero \\ UniversityKano,Email: idrismoore@gmail.coma.
}

\begin{abstract}
Diabetic nephropathy is the leading cause of diabetic complications and end stage renal disease worldwide, especially in Nigeria. This study assessed the clinical utility of urine Albumin to Creatinine ratio (UACR) and urine Haptoglobin to Creatinine ratio (UHCR) in detecting nephropathy among type 2 diabetic patients attending Aminu Kano Teaching Hospital. Eighty (80) type 2 diabetic patients attending Aminu Kano Teaching Hospital were recruited for this study after excluding those with overt proteinuria. Blood sample was collected for quantitative determination of serum creatinine using Jaffe's method while the Urine sample was received for quantitative determination of urine albumin and urine haptoglobin levels. Linear regression model revealed a unit change in urine albumin to creatinine ratio (UACR) and urine haptoglobin to creatinine ratio (UHCR) with a significant reduction in estimated Glomerular Filtration Rate (eGFR) by $2.197 \mathrm{ml} / \mathrm{min}$ and $27.969 \mathrm{ml} / \mathrm{min}$ respectively $(\mathrm{p}<0.05)$ when used while logistic regression model demonstrated that UHCR have $91.7 \%$ sensitivity, $95 \%$ specificity, $98 \%$ positive predictive value and $79 \%$ negative predictive compared to UACR with $83.3 \%$ sensitivity, $75 \%$ specificity, $91 \%$ positive predictive and $60 \%$ negative predictive. Based on these findings, UHCR is a good marker for detecting nephropathy in diabetic patients.
\end{abstract}

Keywords: Diabetic Nephropathy, Urine albumin,Urine Haptoglobin

\section{INTRODUCTION}

$\mathrm{S}_{\mathrm{c}}^{\mathrm{i}}$ ckle Diabetic nephropathy is a microvascular complication of diabetes mellitus and the leading cause of end stage renal disease worldwide. ${ }^{1}$ It is a clinical syndrome characterized by persistent albuminuria, a relentless decline in glomerular filtration rate (GFR), raised arterial blood pressure and relative increased mortality from cardiovascular diseases. ${ }^{2}$

In Nigeria, prevalence rate of diabetes mellitus was estimated to be $5.0 \%$, with $3.0 \%$ prevalence in Northwest Nigeria and $5.5 \%$ prevalence in Southwest Nigeria. ${ }^{4}$ Reports from seven tertiary hospitals in Nigeria show that $3.2 \%$ of diabetic complication accounts for diabetic nephropathy. ${ }^{5}$ Microalbuminura has been the hallmark diagnostic biomarker for early detection of diabetic nephropathy and assessing its associated condition. ${ }^{6}$ Microalbuminuria is defined as urinary albumin excretion between 30 and $300 \mathrm{mg} / 24 \mathrm{hrs}$ or 20 $200 \mu \mathrm{g} / \mathrm{min}$ for timed urine collection. ${ }^{7}$ Though, the 
appropriate sample for microalbumin estimation is 24 hours urine sample but due to the difficulties and errors that may occur during the collection, albumin/creatinine ratio (UACR) in early morning spot urine was adopted as a diagnostic alternative to correct for limitations. ${ }^{8}$ However, studies have shown that urinary albumin to creatinine ratio is neither sensitive nor specific for early detection of diabetic nephropathy. ${ }^{9,10}$ Studies have also shown that many patients who have microalbuminuria at one point in time might not have it when measured later and as such makes it a poor predictor of the development of macroalbuminuria. ${ }^{11}$

Studies on diabetic induced transgenic mice also showed that haptoglobin is a major determinant of the development and progression of diabetic renal disease. ${ }^{12}$ In a recent study, urinary haptoglobin was reported to predicts renal progression independent of albuminuria and also improve the predictive performance of albuminuria beyond traditional risk factors in Asians with type 2 diabetes mellitus. ${ }^{10}$ Haptoglobin is an alpha-2 sialo glycoprotein that is synthesized in the liver but other tissues including kidney have been shown to express it. ${ }^{13}$ The early detection of diabetic nephropathy is of paramount importance to provide appropriate therapy that will prevent evolution to end stage renal disease most especially among low and middle income countries like Nigeria where facilities to cater for such patient may be prohibitive interms of availability and cost. In this regard, haptoglobin has recently been identified as a predictor of early renal injury before the manifestation of chronic kidney disease and end stage renal disease. Such a predictor, if available for early detection of renal injury may permits targeted treatment with more aggressive therapies at earlier stage that will prevent deterioration in kidney function. This study therefore aimed to assess the diagnostic utility of urinary haptoglobin/creatinine (UHCR) ratio for detecting diabetic nephropathy.

\section{MATERIALS AND METHODS}

This cross-sectional study was conducted between July 2018 to July 2019 among Type 2 diabetic patients attending Aminu Kano Teaching Hospital for follow up treatment. Kano State is located at $11^{\circ} 30^{\prime} \mathrm{N} 8^{\circ} 30^{\prime} \mathrm{E}$ in the Northern Nigeria. It was created on May 27, 1967 and bordered by Katsina State to the north-west, Jigawa State to the north-east, Bauchi State to the south-east and Kaduna State to the south-west. The capital of
Kano State is Kano. It has a total Area of $20,131 \mathrm{Km}^{2}$ with an estimated population of $11,058,300$ and density of $470 / \mathrm{Km}^{2}$. An estimated sample size of 80 was made based on the prevalence rate of diabetes in Nigeria using the formula proposed by Susan et al., 2015. ${ }^{14}$ Recruitment was by systematic random sampling after obtaining an informed consent from the study subjects. Subjects presenting with the following conditions were excluded from the study: insulin therapy, pregnancy, cardiovascular disease, urinary tract infection, menstruation and cigarette smoking. A structured pretested questionnaire was used to obtain relevant disease and treatment history. Ethical approval was sought from the institutional research committee reference number NHREC/ $21 / 08 / 2008 /$ AKTH/EC/ 2252 and $\mathrm{AKTH} / \mathrm{MAC} / \mathrm{SUB} / 12 \mathrm{~A} / \mathrm{P}-3 / \mathrm{VI} / 2352$. Urine and Blood samples were collected from all recruited participants.

\section{Statistical analysis}

Data analysis was done using Statistical Package for Social Sciences (SPSS) version 16.0 Software. The measured values for urinary albumin, haptoglobin and creatinine concentrations were presented as mean \pm standard deviation. UACR and UHCR were calculated by dividing the urine albumin and urine haptoglobin values by the urinary creatinine values. Regression analysis was used to determine the clinical utility of UACR and UHCR for detecting DN. The measured percentage values for $\mathrm{HbAl} \mathrm{c}$ were presented as mean \pm standard deviation. Relationship between $\mathrm{HbAlc}$ and UACR ratio as well as relationship between $\mathrm{HbAlc}$ and UHCR were assessed using Spearman Correlation coefficient. Statistical significance was set at $\mathrm{p}<0.05$.

\section{Laboratory Methods Urinalysis}

Urinalysis was be carried out using urine reagent strip by Cortez Diagnostics, Inc. ${ }^{15}$

\section{Glycated Haemoglobin}

HbA1c was assayed using fluorescence immunoassay method by Finecare ${ }^{\text {TM }} .^{16}$

\section{Haptoglobin}

Haptoglobin was assayed using ELISA method by AssayMax $^{\mathrm{TM}}$ Human Haptoglobin ELISA Kit. ${ }^{17}$

\section{Microalbumin}

Microalbumin was assayed using Immunoturbidimetric method by Microalbumin kit manufactured by Fortress 
Diagnostics Limited. ${ }^{18}$

\section{Creatinine}

Creatinine was estimated using modified Jaffe method. ${ }^{19}$

\section{Estimated glomerular filtration rate (eGFR)}

Kidney function was assessed by estimated glomerular filtration rate (eGFR) using Cockcroft and Gault formula. ${ }^{20}$

\section{Quality assurance}

All analytical tests were done according to the standard operating procedures. It involved the use of inter and intra-run of control sera along with the samples. Pre-analytical, analytical and post analytical precautions were observed.

Table 1: Age, Sex and BMI of Study Subjects

\begin{tabular}{lllc}
\hline Parameters & & Number & Frequency (\%) \\
& & & \\
\hline Gender & Male & 35 & 44 \\
& Female & 45 & 56 \\
Age ( $\overline{\mathbf{x}} \pm$ SD) & $53.78 \pm 9.5$ years & & \\
\hline BMI $(\overline{\mathbf{x}} \pm$ SD) \\
$\begin{array}{l}\text { Duration of } \\
\text { Diabetes }(\overline{\mathbf{x}} \pm \text { SD) }\end{array}$ & $(\mathrm{Kg} / \mathrm{m} 2) 27.3 \pm 5.3$ & Peak: 36 (45\%) subjects 6-10 yrs \\
& &
\end{tabular}

Table 2: Glycaemic Control (Hba1c) of Study Participants

\begin{tabular}{lll}
\hline $\mathbf{( \overline { \mathbf { x } } \pm \text { SD }} 6.6 \pm 2.0^{0}$, & & \\
& Number Frequency & $\mathbf{( \% )}$ \\
Good control $(\leq 5.7)$ & 31 & 39 \\
Borderline $(5.7-6.4)$ & 13 & 16 \\
Poor control $(\geq 6.5)$ & 36 & 45 \\
\hline
\end{tabular}

Table 3: CKD Staging (NKF, 2002)

\begin{tabular}{|c|c|c|c|}
\hline \\
\hline \multicolumn{4}{|l|}{$(\overline{\mathrm{x}} \pm \mathrm{SD}$ eGFR: $98.4 \pm 40.3 \mathrm{ml} / \mathrm{min} / 1.73 \mathrm{~m}$} \\
\hline & Stage $1(>90 \mathrm{ml} / \mathrm{min})$ & 20 & 25 \\
\hline & Stage $2(60.0-89.9 \mathrm{~m} / \mathrm{min})$ & 53 & 66 \\
\hline & Stage $3(30.0-59.9 \mathrm{~m} / \mathrm{min})$ & 7 & 9 \\
\hline
\end{tabular}

Table 4: Mean and Median of Bio-Chemical Characteristics

\begin{tabular}{lll}
\hline Characteristics & Mean \pm SD & Median(IQR) \\
& & \\
\hline Hap $(\mathrm{ng} / \mathrm{ml})$ & $93.6 \pm 70.1$ & $68.8(25.0-164.4)$ \\
UACR $(\mathrm{mg} / \mathrm{g})$ & $78.3 \pm 89.1$ & $51.5(28.3-78.0)$ \\
UHCR $(\mathrm{ng} / \mathrm{g})$ & $908.9 \pm 972.7$ & $529.0(119.0-1414.0)$ \\
\hline
\end{tabular}

Table 5 Comparing Biochemical Characteristics According to CKD Stages

\begin{tabular}{lccccc}
\hline Characteristics & Stage 1 & Stage 2 & \multicolumn{2}{c}{ Stage 3 } & \multicolumn{2}{c}{ Kruskal Walis p-value } \\
\hline Urine Albumin & $5.3(4.5-6.0)$ & $7.5(6.8-10.0)$ & $19.5(19.5-19.5)$ & 61.023 & 0.001 \\
Haptoglobin & $21.3(11.3-25.0)$ & $140.6(58.8-172.2)$ & $193.8(187.5-197.5)$ & 60.934 & 0.001 \\
\hline
\end{tabular}

Table 6: Validity of UHCR for diabetic Nephropathy

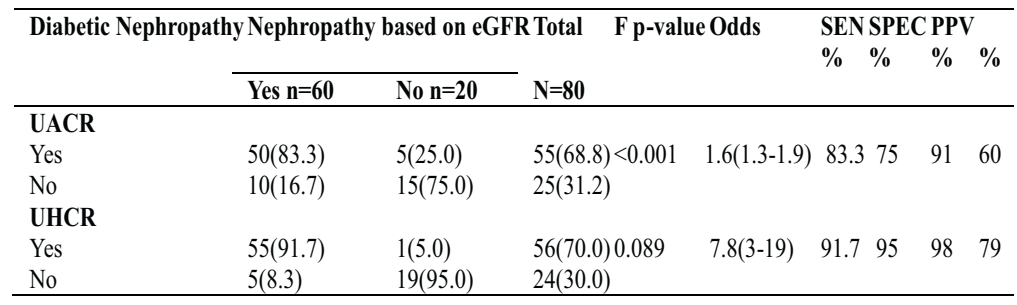

\section{DISCUSSION}

The present study recruited a total of eighty (80) type 2 diabetic patients of which $43.8 \%$ (35) were males and the remaining $56.2 \%$ (45) were the female participants resulting in 1:1.2 male to female ratio. The higher number of female participants was in keeping with studies done on diabetic patients in the same center by Umar in 2016 as well as in Abakaliki. $^{21}$

The mean age of the participant was $53.8 \pm 9.5$ years with the mean duration of the disease of $8.5 \pm 4.8$ years which is in concordance with the findings of Uloko et al. ${ }^{22}$ This finding is a suggests that middle age is the peak age incidence for diabetes in this environment. The mean body mass index of the study population was $27.3 \pm 5.3 \mathrm{~kg} / \mathrm{m}^{2}$ comprising of $37.6 \%$ of both underweight and normal weight while the remaining $62.5 \%$ were overweight and obese patients.

HbAlcdetermination documented a mean value of $6.6 \pm 2.0 \%$ with good glycaemic control recorded in $39 \%$ against $61.2 \%$ with poor glycaemic control. This connotes that the participants showed suboptimal glycaemic control which is in agreement with the study of Uloko $e t \mathrm{al}^{22}$ that most Nigerians diabetics have suboptimal glycemic control.

We observed a significant increasein the urine albumin, urine haptoglobin, glycated haemoglobin $(\mathrm{P}<0.05)$ across the stages of chronic kidney disease in this studywhich agrees with a study that higher level of albuminuria, glycated haemoglobin and haptoglobinuria are recorded in patients that developed early renal function decline. ${ }^{9}$ Linear regression model was used to predict diabetic nephropathy using UACR and UHCR. The analysis showed that eGFR reduces by $2.197 \mathrm{ml} / \mathrm{min}$ in a unit change of UACR compared to 27.969 $\mathrm{ml} / \mathrm{min}$ reduction in eGFR in a unit change of UHCR. This infers that UACR and UHCR predict nephropathy in type 2 diabetic patients 
independently, though UHCR is found to have more predictive ability than UACR as equally reported in the previous studies in USA, ${ }^{9}$ and Asia. ${ }^{10} \mathrm{We}$ then evaluated the prediction accuracy of UHCR independent of UACR and this revealed that UHCR predictive ability significantly out performed UACR in the prediction of diabetic.

We further correlated HbA1C with UACR as well as UHCR and this study demonstrate a strong positive relationship exists with UHCR correlating having a stronger correlation coefficient $(r=0.739)$ than UACR. This strong positive relationship was equally observed in a previous study among Asians, ${ }^{10}$ however is contrary to the study of Bhensdadia et $a l .{ }^{9} 2013$ that reported a weak positive relationship between UHCR and UACR.

Using logistic regression analysis, eGFR predicted 60 participants of the study population to have diabetic nephropathy. UACR predicted $83.3 \%(50)$ to have diabetic nephropathy with $83.3 \%$ sensitivity, $75 \%$ specificity, $91 \%$ positive predictive value and $60 \%$ negative predictive value while UHCR predicted $91.7 \%(55)$ to have diabetic nephropathy with $91.7 \%$ sensitivity, 95\% specificity, 98\% positive predictive power and $79 \%$ negative predictive power at $p<0.05$ level of significance. UHCR significantly predicts diabetic nephropathy.

\section{CONCLUSION}

This study for the first time established that UHCR has better diagnostic utility than UACR exhibited a very good positive correlation with glycaemic control. Based on its high sensitivity and specificity we therefore recommend its use in screening for nephropathy in diabetic patients.

Further multicenter studies and longitudinal studies are also recommended.

\section{Conflict of Interest}

None declared.

\section{REFERENCES}

1. Samuel NU. The role of novel biomarkers in predicting diabetic nephropathy: a review. Int J Nephrol Renovasc Dis. 2017; 10:221-231.

2. Rehman G, Hamayun M. Studies on diabetic nephropathy and secondary disease in type-1 diabetes. Int J Diabetes Dev Ctries. 2004; 24:50-55.
3. IDF Diabetes Atlas Group. Update of mortality attributable to diabetes for the IDF Diabetes Atlas: estimates for the year 2011. Diabetes Res Clin Pract. 2013;100(2):277-9.

4. Andrew UE, Musa BM, Ramalan MA, Ibrahim DG, Mohammed BM, Fabian HP, et al. Prevalence and risk factors for diabetes mellitus in Nigeria: A systemic review and meta-analysis. Diabetes Therapy. 2018;9(3):1307-1316.

5. Chinenye S, Young E. State of Diabetes Care in Nigeria. The Nigeria Health Journal. 2011;11(4):101-106.

6. Uwaezuoke SN. Prevention of diabetic nephropathy in children and adolescents: how effective are the current strategies? Int J Diabetol Vasc Disease Res. 2015;1(5):1-5.

7. Bunza FU, Mainasara AS, Dallatu MK, Bunza JM, Wasagu IZ. Prevalence of Microalbuminuria among diabetic patients in Usman Danfodiyo University Teaching Hospital, Sokoto. Bayero J Pure Appl Sci. 2014;7(1):1-5.

8. Guy M, Borzomato JK, Newall RG, Kalra PA, Price CP. Protein and albumin-to-creatinine ratios in random urines accurately predict $24 \mathrm{~h}$ protein an albumin loss in patients with kidney disease. Ann Clin Biochem. 2009; 46:468-476.

9. Bhensdadia NM, Hunt KJ, Lopes-Virella MF, Michael TJ, Mataria MR, Alge JL, et al. Urine haptoglobin levels predict early renal functional decline in patients with type 2 diabetes. Kidney Int. 2013;83(6):1136-43.

10. Jian-Jun L, Sylvia L, Melvin DS, Resham LG, Su CM. Urinary haptoglobin predicts rapid renal function decline in Asians with Type 2 diabetes and early kidney disease. J Clin Endocrinol Metab. 2016;101(10):3794-3802.

11. Araki S, Haneda M, Sugimoto T. Factors associated with frequent remission of microalbuminuria in patients with type 2 diabetes. Diabetes. 2005; 54:2983-2987.

12. . Nakhoul FM, Miller-Lotan R, Awad H, Asleh R, Jad $\mathrm{K}$, Nakhoul N, et al. Pharmacogenomic effect of vitamin $\mathrm{E}$ on kidney structure and function in transgenic mice with the haptoglobin 2-2 genotype and diabetes mellitus. Am J Physiol Renal Physiol. 2009; 296:830-838.

13. Wobeto VP, Zaccariotto TR, Sonati MF. Polymorphism of human haptoglobin and its clinical importance. Genet Mol Biol. 2008;31:602-608.

14. Susan R, Nigel S, Ana IC. Applying the principles: formula for determining sample size. Management Research. 2015; 1:1-4.

15. Free AH and Free HM. Urinalysis, Critical Discipline of Clinical Science. CRC Crit Rev Clin Lab Sci. 1972;3(4):481-531. 
16. Bunn HF. Nonenzymatic glycosylation of protein: relevance to diabetes. Am J Med. 1981; 70:331-338.

17. Van Vlierberghe H, Langlois M, Delanghe J. Clin Chim Acta. 2004;345(1):35-42.

18. Elvin LD, Bakkeren JA, Jansen MJ, Angelino CM, Nobel E, Munster PJ.Screening for microalbuminuria in patients with diabetes mellitus: frozen storage of urine samples decreases their albumin content. Clin Chem. 1989;35(2):308-310.

19. Jaffe XZ. Creatinine determination according to Jaffe. Hoppe Seylers Z Physiol Chem. 1886; 10:391.

20. Cockcroft DW, Gault MH. Prediction of creatinine clearance from serum creatinine. Nephrology. 1976; $16: 31-41$.

21. Ibekwe MU. Pattern of type 1 diabetes mellitus in Abakaliki Southeastern, Nigeria. Pediatr Oncall. 2011;8(7):59-62.

22. Uloko AE, Ofoegbu EN, Sunday C, Fasanmade OA, Fasanmade AA, Ogbera AO, et al. Profile of Nigerians with diabetes mellitus: results of a multicenter study. Indian J Endocrinol Metab. 2012;16(4):558-564. 